\title{
Erratum to: Myo-inositol is a promising treatment for the prevention of ovarian hyperstimulation syndrome (OHSS): an animal study
}

\author{
Guluzar Arzu Turan' ${ }^{1}$ Fatma Eskicioglu ${ }^{2}$ Oya Nermin Sivrikoz ${ }^{3}$. \\ Hakan Cengiz $^{4,5} \cdot$ Saban Adakan $^{1} \cdot$ Esra Bahar Gur ${ }^{1} \cdot$ Sumeyra Tatar ${ }^{1}$. \\ Nur Sahin ${ }^{1} \cdot$ Osman Yilmaz $^{6}$
}

Published online: 29 January 2016

(C) Springer-Verlag Berlin Heidelberg 2016

\section{Erratum to: Arch Gynecol Obstet (2015) \\ 292:1163-1171 \\ DOI 10.1007/s00404-015-3747-5}

We regret a typo error in the official publication of "Materials and methods", animals section's last paragraph. In this section, the eighth line amount of $5 \mathrm{mM}$
Evans Blue dye introduced through the jugular vein should be $0.2 \mathrm{ml}$ instead of $2 \mathrm{ml}$. The correct sentence is given below.

The neck was dissected and the jugular vein was injected with $0.2 \mathrm{ml}$ of $5 \mathrm{mM}$ Evans Blue (Sigma-Aldrich, USA) to evaluate vascular permeability.

The online version of the original article can be found under doi:10.1007/s00404-015-3747-5.

Guluzar Arzu Turan

arzuturan74@yahoo.com

1 Department of Obstetrics and Gynecology, Medical School, Sifa University, Sanayi cad no:7, 35100 Bornova, Izmir, Turkey

2 Department of Obstetrics and Gynecology, Medical School, Celal Bayar University, 45030 Manisa, Turkey

3 Department of Pathology, Medical School, Sifa University, Sanayi cad no:7, 35100 Bornova, Izmir, Turkey

4 Biostatistics and Medical Informatics, Medical School, Sifa University, Ankara Cad. No:45, 35100 Bayrakli, Izmir, Turkey

5 Molecular Medicine, Institute of Health Science, Dokuz Eylül University, Mithatpasa cad. No:1606 inciraltı yerleskesi, 35340 Balcova, Izmir, Turkey

6 Department of Laboratory Animal Science, Medical School, Dokuz Eylul University, Mithatpasa cad. No:1606 inciralt1 yerleskesi, 35340 Balcova, Izmir, Turkey 